\title{
Swiss Spaghetti Harvest and JKACAP SCIE
}

\author{
Geon Ho Bahn \\ Editor-in-Chief, Korean Academy of Child and Adolescent Psychiatry
}

On April 1, 1957, the BBC broadcasted a news article about a family in southern Switzerland harvesting spaghetti from the family "spaghetti tree." Afterwards, a number of viewers contacted the $\mathrm{BBC}$ for advice on growing their own spaghetti trees. This "spaghetti tree" news bulletin was one of the best April Fools' Day jokes ever made [1]. In the past, April 1 was the first day of the New Year, meaning that the origin of April Fools' Day may be related to the idea of people wanting a pleasant start to the New Year.

The Journal of the Korean Academy of Child and Adolescent Psychiatry (JKACAP), Vol 30, No 2, is being published on April 1, April Fools' Day. The editorial committee members of KACAP are currently attempting to list JKACAP as a SCIE journal but have been encountering difficulty and have not yet been successful. Should the committee members give up? Humor is one of the many tools humans use to overcome hardships. Editorial committee members also need humor!

Since Gilles de la Tourette described nine patients with what is now known as Tourette's syndrome in 1885 , no cause or clear treatment mechanism has been identified yet for this syndrome. This is a common occurrence in the field of pediatric psychiatry, where most names of disorders or syndromes have been used and accepted for a long time. Seok Hyun Nam, Juhyun Park, and Tae Won Park's study "Clinical aspects of premonitory urges in patients with Tourette's disorder" is a review article that attempted to determine typical symptoms of Tourette's disorder. In JKACAP Vol 28, No 1 published on January 1, 2017, Corwin [2] and scholars from the Academy on Violence and Abuse [3-5] published articles concerning childhood trauma and maltreatment. Studies concerning abuse and violence investigate the social phenomenon, rather than specific diseases with definite pathogens or etiologies. That is why studying the psychological disorders related to abuse is difficult. This prompted Lee et al. to publish research concerning the "perception of child abuse and disciplinary practices among parents who were abused as children compared with the general population."

In Korea, the most commonly used drugs for ADHD treatment are derivatives of methylphenidates. In this volume, Kee Jeong Park and Hyo-Won Kim's study titled, "Clinical and neuropsychological factors associated with treatment response and adverse events of atomoxetine in children with

This is an Open Access article distributed under the terms of the Creative Commons Attribution Non-Commercial License (https://creativecommons.org/licenses/by-nc/4.0) which permits unrestricted non-commercial use, distribution, and reproduction in any medium, provided the original work is properly cited.
ADHD" is published. About ten years ago, a KACAP task force team developed a new assessment tool-the computerized comprehensive attention test (CAT) - that is able to evaluate various types of attention and working memory in children and adolescents [6]. At that time, the age norm for CAT was 15 years or younger. In Yoo et al.'s study titled "Developmental Trajectories of Attention in Normal Korean Population," authors expanded the diagnostic norm for CAT to people aged 16 to 40 . The authors expressed their hope that CAT will be used to assess adults with ADHD. In a Book Review, Jaesuk Jung introduced a book titled "Reading in the brain" written by Stanislas Dehaene, a famous French cognitive neuroscience scholar. Dr. Jung is also a well-respected child psychiatrist and has developed learning disability diagnostic tools specified for mathematics as well as Korean writing and reading disorders. The book explains why humans are the only species that have developed different cultures.

In the 1480s, Leonardo da Vinci designed the "aerial screw" for vertical flight. If Leonardo had published his work on the flying machine on April 1, people would have thought it was a prank. Then, in 1936, Heinrich Focke designed the world's first practical transverse twin-rotor helicopter, the FockeWulf Fw61. With this design, a joke turned into a reality. Possibly, genetic modification research can one day lead to a spaghetti vine tree, and JKACAP could be a SCIE magazine. The task of upgrading JKACAP is tough and the future is unclear. Therefore, April Fools' Day must continue.

\section{REFERENCES}

1) Wikipedia. Spaghetti-tree hoax. [edited] 2019 Jan 23 [cited 2019 Mar 28] Available from URL:https://en.wikipedia.org/wiki/Spaghetti-tree hoax.

2) Corwin DL. Violence and abuse: what child psychiatrists need to know. J Korean Acad Child Adolesc Psychiatry 2017;28:2-3.

3) Wiet S. Origins of addiction predictably embedded in childhood trauma: a neurobiological review. J Korean Acad Child Adolesc Psychiatry 2017;28:4-13.

4) Keeshin B, Strawn JR. Pharmacologic considerations for youth with posttraumatic stress disorder. J Korean Acad Child Adolesc Psychiatry 2017;28:14-19.

5) Durrant JE, Ensom R. Twenty-five years of physical punishment research: what have we learned? J Korean Acad Child Adolesc Psychiatry 2017;28:20-24.

6) Yoo HI, Lee JS, Kang SH, Park EH, Jung JS, Kim BN, et al. Standardization of the comprehensive attention test for the Korean children and adolescents. J Korean Acad Child Adolesc Psychiatry 2009;20:68-75 